\title{
Validity of PEC Approximation for On-Body Propagation
}

Kammersgaard, Nikolaj Peter Iversen; Kvist, Søren Helstrup; Thaysen, Jesper; Jakobsen, Kaj Bjarne

Published in:

Proceedings of EuCAP 2016

Publication date:

2016

Document Version

Peer reviewed version

Link back to DTU Orbit

Citation (APA):

Kammersgaard, N. P. I., Kvist, S. H., Thaysen, J., \& Jakobsen, K. B. (2016). Validity of PEC Approximation for On-Body Propagation. In Proceedings of EuCAP 2016 IEEE.

\section{General rights}

Copyright and moral rights for the publications made accessible in the public portal are retained by the authors and/or other copyright owners and it is a condition of accessing publications that users recognise and abide by the legal requirements associated with these rights.

- Users may download and print one copy of any publication from the public portal for the purpose of private study or research.

- You may not further distribute the material or use it for any profit-making activity or commercial gain

- You may freely distribute the URL identifying the publication in the public portal

If you believe that this document breaches copyright please contact us providing details, and we will remove access to the work immediately and investigate your claim. 


\title{
Validity of PEC Approximation for On-Body Propagation
}

\author{
Nikolaj P. B. Kammersgaard*, Søren H. Kvist ${ }^{\dagger}$, Jesper Thaysen ${ }^{\dagger}$ and Kaj B. Jakobsen* \\ npivka@elektro.dtu.dk, skvistegnresound.com, jthaysen@gnresound.com, kbjelelektro.dtu.dk
}

*Department of Electrical Engineering, Electromagnetic Systems, Technical University of Denmark, Ørsteds Plads, Building 348, DK-2800 Kgs. Lyngby, Denmark

${ }^{\dagger}$ GN ReSound A/S, Lautrupbjerg 7, DK-2750 Ballerup, Denmark

\begin{abstract}
Many articles on on-body propagation assumes that the human body can be approximated by a perfect electric conductor (PEC) instead of the actual constitutive parameters of the human body, which is that of a lossy dielectric. This assumption is investigated in this article through comparison of the scattering of a plane wave at oblique incidence by a PEC and a lossy dielectric cylinder. The investigation shows that the validity of the assumption depends on the polarization of the plane wave, the angle of incidence, and the region of interest.
\end{abstract}

\section{INTRODUCTION}

The area of on-body propagation has been of high interest in recent years. Wireless communications for on-body devices serves as one of the enabling factors in the emerging commercial area of wearables.

Numerous investigations have been made on the on-body propagation and many models have been proposed. In many of these the body is approximated by a perfect electric conductor (PEC) of some shape, [1]-[5]. Often these models justify directly or indirectly this assumption based on [6]. But since [6] is concerned only with the disturbance in the channel between two off-body antennas this seems to be a poor validation.

The purpose of this work is to investigate if modeling the body as a PEC is a valid assumption. Furthermore, if the assumption might be valid under certain other assumptions.

The on-body propagation will be investigated by the use of the exact solution to the fields around an infinitely long cylinder. The fields will be calculated for a PEC cylinder and for a human body average cylinder. The material parameters of the human body are documented in [7]. The average material parameters in [8] is used $\left(\epsilon_{\mathrm{r}}=39.2\right.$ and $\left.\sigma=1.8 \mathrm{~S} / \mathrm{m}\right)$. The cylinder has a radius of $a=80 \mathrm{~mm}$, which is similar to the radius of the leg or the radius of the head. The fields are calculated for both TM and TE polarization and at three different angles of incidence.

\section{THEORY}

The infinitely long lossy dielectric cylinder is located in free space. A plane wave is incident and propagating in the direction given by $\hat{d}=(0, \sin \alpha, \cos \alpha)$ as seen in Fig. 1 . The propagation constant in the cylinder and in free space

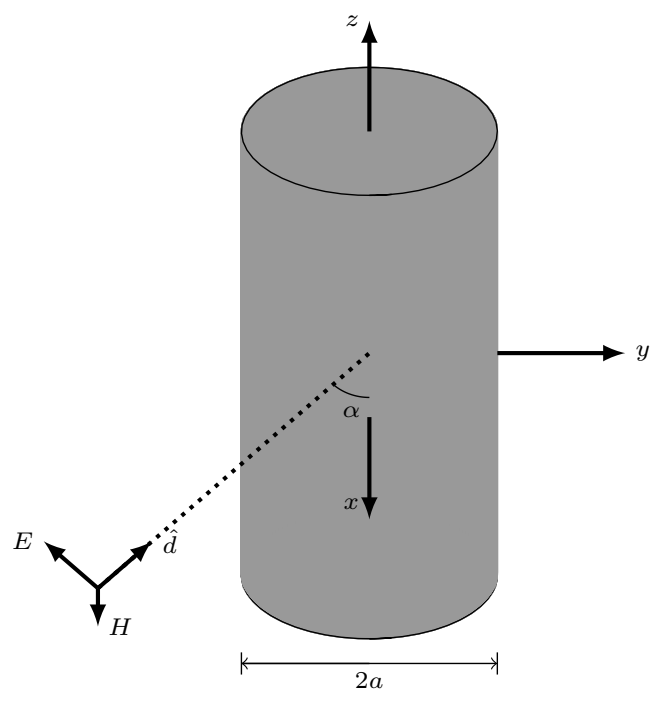

Fig. 1. The geometry of the infinitely long dielectric cylinder model.

are $k_{1}$ and $k$, respectively. Two other propagation constants are defined as $k^{\prime}=k \sin \alpha$ and $k_{1}^{\prime}=\sqrt{k_{1}^{2}-k^{2} \cos ^{2} \alpha}$ The electric and magnetic fields outside the cylinder incident by a transverse magnetic (TM) plane wave are given by the following formulas obtained from [9], [10]:

$$
\begin{gathered}
E_{\rho}=-j k \cos \alpha \frac{\partial u}{\partial \rho}-\frac{j \mu \omega}{\rho} \frac{\partial v}{\partial \phi} \\
E_{\phi}=-\frac{j k \cos \alpha}{\rho} \frac{\partial u}{\partial \phi}+j \mu \omega \frac{\partial v}{\partial \rho} \\
E_{\mathrm{z}}=k^{\prime 2} u \\
H_{\rho}=\frac{j k^{2}}{\mu \omega \rho} \frac{\partial u}{\partial \phi}-j k \cos \alpha \frac{\partial v}{\partial \rho} \\
H_{\phi}=-\frac{j k^{2}}{\mu \omega} \frac{\partial u}{\partial \rho}-\frac{j k \cos \alpha}{\rho} \frac{\partial v}{\partial \phi} \\
H_{\mathrm{z}}=k^{\prime 2} v
\end{gathered}
$$

where a common factor of $e^{-j k z \cos \alpha}$ has been suppressed as well as a time dependency of $e^{j \omega t}$. To obtain $E_{\rho}$ and $E_{\phi}$ inside the cylinder the permeability $\mu$ must be replaced by 


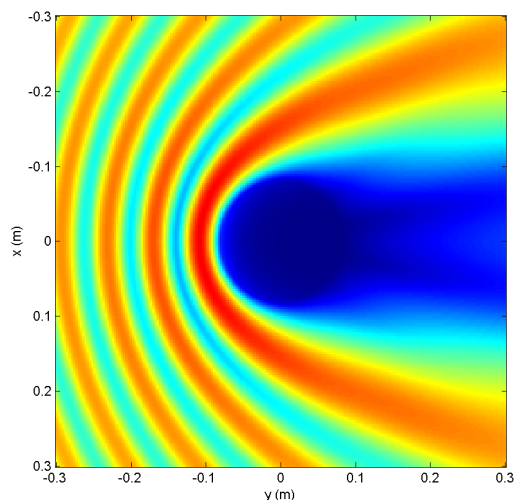

(a) $\alpha=90^{\circ}$

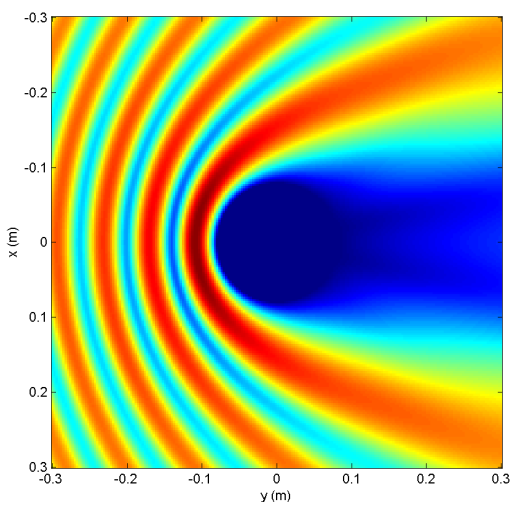

(d) $\alpha=90^{\circ}$

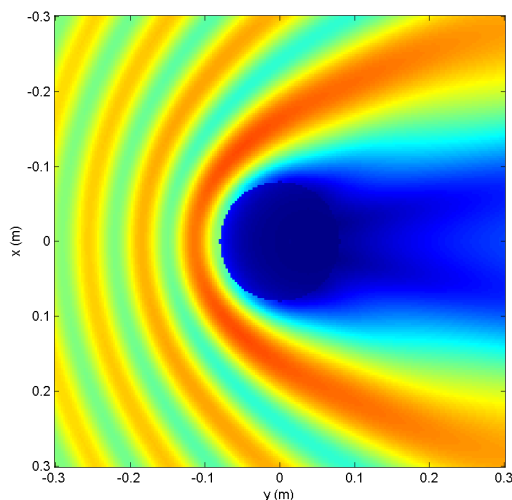

(b) $\alpha=60^{\circ}$

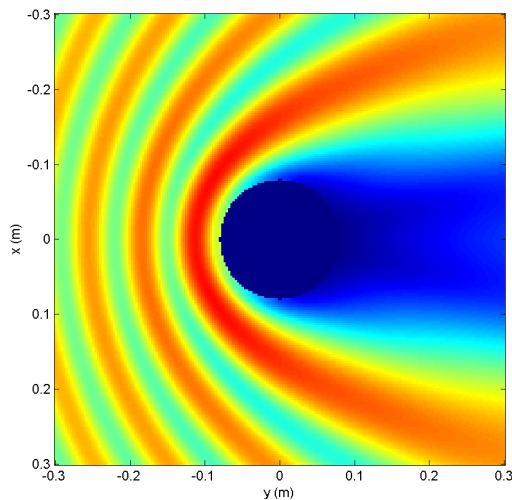

(e) $\alpha=60^{\circ}$

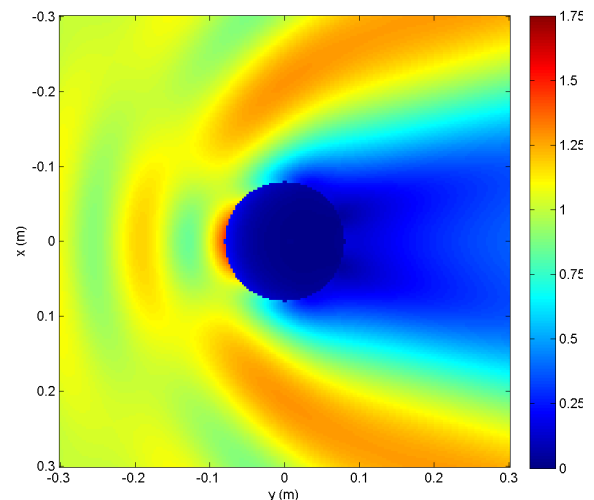

(c) $\alpha=30^{\circ}$

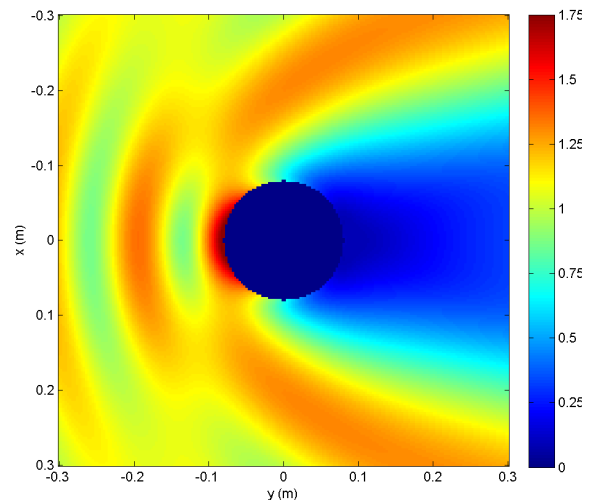

(f) $\alpha=30^{\circ}$

Fig. 2. Electric field strength $(\mathrm{V} / \mathrm{m})$ plot for TM plane wave incident on a human-body average (a, b, c) and PEC (d, e, f) cylinder at different angles.

$\mu_{1}$. To obtain $E_{\mathrm{z}}$ and $H_{\mathrm{z}}$ inside the cylinder the propagation constant $k^{\prime}$ must be replaced by $k_{1}^{\prime}$. To obtain $H_{\rho}$ and $H_{\phi}$ inside the cylinder $\mu$ and $k$ must be replaced by $\mu_{1}$ and $k_{1}$ in the terms involving $u$ and remain the same for the terms involving $v$. For $\rho>a$ the scalar potentials $u$ and $v$ are given by [9]:

$$
\begin{gathered}
u=\frac{-E_{0} \sin \alpha}{k^{\prime 2}} \sum_{n=-\infty}^{\infty}\left(J_{n}\left(k^{\prime} \rho\right)-a_{n} H_{n}^{(2)}\left(k^{\prime} \rho\right)\right) e^{-j n \phi} \\
v=\frac{-E_{0} \sin \alpha}{k^{\prime 2}} \sum_{n=-\infty}^{\infty} c_{n} H_{n}^{(2)}\left(k^{\prime} \rho\right) e^{-j n \phi}
\end{gathered}
$$

and for $\rho<a$ by:

$$
\begin{aligned}
& u=\frac{-E_{0} \sin \alpha}{k^{\prime 2}} \sum_{n=-\infty}^{\infty} b_{n} J_{n}\left(k_{1}^{\prime} \rho\right) e^{-j n \phi} \\
& v=\frac{-E_{0} \sin \alpha}{k^{\prime 2}} \sum_{n=-\infty}^{\infty} d_{n} J_{n}\left(k_{1}^{\prime} \rho\right) e^{-j n \phi}
\end{aligned}
$$

where $a_{n}, b_{n}, c_{n}$, and $d_{n}$ are constants chosen to ensure the continuity of the tangential components of the E-fields and
H-fields across the boundary. The constants are given by:

$$
\begin{aligned}
a_{n}= & \frac{J_{n}\left(k^{\prime} a\right)}{\Delta H_{n}^{(2)}}\left\{\left[\frac{\mu_{1}}{\mu k_{1}^{\prime} a} \frac{J_{n}^{\prime}\left(k_{1}^{\prime} a\right)}{J_{n}\left(k_{1}^{\prime} a\right)}-\frac{1}{k^{\prime} a} \frac{H_{n}^{(2) \prime}\left(k^{\prime} a\right)}{H_{n}^{(2)}\left(k^{\prime} a\right)}\right]\right. \\
& \cdot\left[\frac{k_{1}^{2}}{k^{2}} \frac{\mu}{\mu_{1} k_{1}^{\prime} a} \frac{J_{n}^{\prime}\left(k_{1}^{\prime} a\right)}{J_{n}\left(k_{1}^{\prime} a\right)}-\frac{1}{k^{\prime} a} \frac{J_{n}^{\prime}\left(k^{\prime} a\right)}{J_{n}\left(k^{\prime} a\right)}\right] \\
& \left.-\left[\frac{1}{\left(k^{\prime} a\right)^{2}}-\frac{1}{\left(k_{1}^{\prime} a\right)^{2}}\right]^{2} n^{2} \cos ^{2} \alpha\right\} \\
b_{n}= & \frac{k^{\prime 2}}{k_{1}^{\prime 2}}\left[J_{n}\left(k^{\prime} a\right)-a_{n} \frac{H_{n}^{(2)}\left(k^{\prime} a\right)}{J_{n}\left(k_{1}^{\prime} a\right)}\right] \\
c_{n}= & -\frac{2 k n \cos \alpha}{\Delta \mu \omega \pi\left(k^{\prime} a\right)^{2}} \frac{1}{H_{n}^{(2)}\left(k^{\prime} a\right)}\left[\frac{1}{\left(k^{\prime} a\right)^{2}}-\frac{1}{\left(k_{1}^{\prime} a\right)^{2}}\right] \\
d_{n}= & \frac{k^{\prime 2}}{k_{1}^{\prime 2}} c_{n} \frac{H_{n}^{(2)}\left(k^{\prime} a\right)}{J_{n}\left(k_{1}^{\prime} a\right)}
\end{aligned}
$$

where

$$
\begin{aligned}
\Delta= & {\left[\frac{\mu_{1}}{\mu k_{1}^{\prime} a} \frac{J_{n}^{\prime}\left(k_{1}^{\prime} a\right)}{J_{n}\left(k_{1}^{\prime} a\right)}-\frac{1}{k^{\prime} a} \frac{H_{n}^{(2) \prime}\left(k^{\prime} a\right)}{H_{n}^{(2)}\left(k^{\prime} a\right)}\right] } \\
& \cdot\left[\frac{k_{1}^{2}}{k^{2}} \frac{\mu}{\mu_{1} k_{1}^{\prime} a} \frac{J_{n}^{\prime}\left(k_{1}^{\prime} a\right)}{J_{n}\left(k_{1}^{\prime} a\right)}-\frac{1}{k^{\prime} a} \frac{H_{n}^{(2) \prime}\left(k^{\prime} a\right)}{H_{n}^{(2)}\left(k^{\prime} a\right)}\right] \\
& -\left[\frac{1}{\left(k^{\prime} a\right)^{2}}-\frac{1}{\left(k_{1}^{\prime} a\right)^{2}}\right]^{2} n^{2} \cos ^{2} \alpha .
\end{aligned}
$$




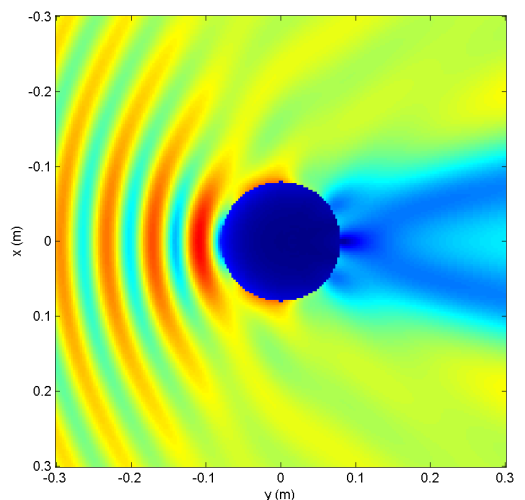

(a) $\alpha=90^{\circ}$

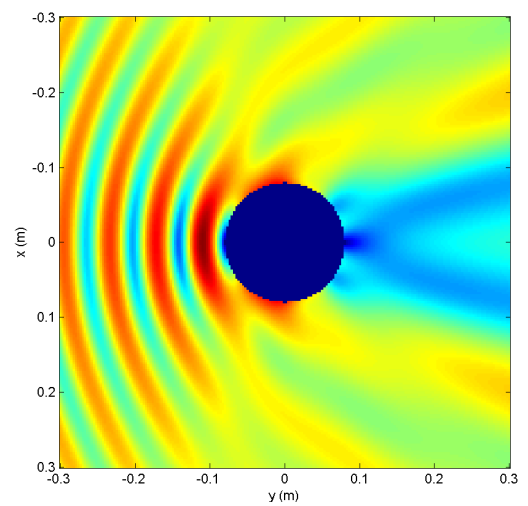

(d) $\alpha=90^{\circ}$

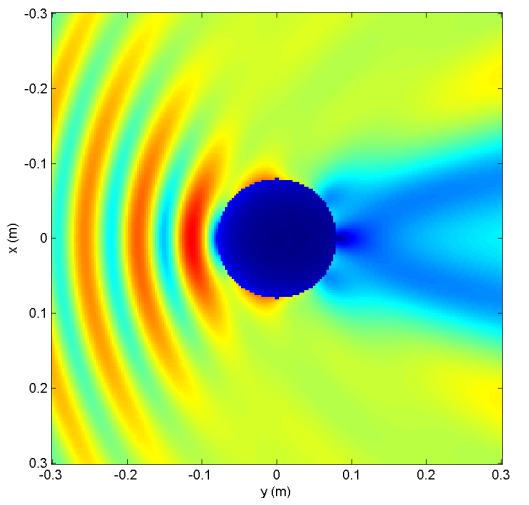

(b) $\alpha=60^{\circ}$

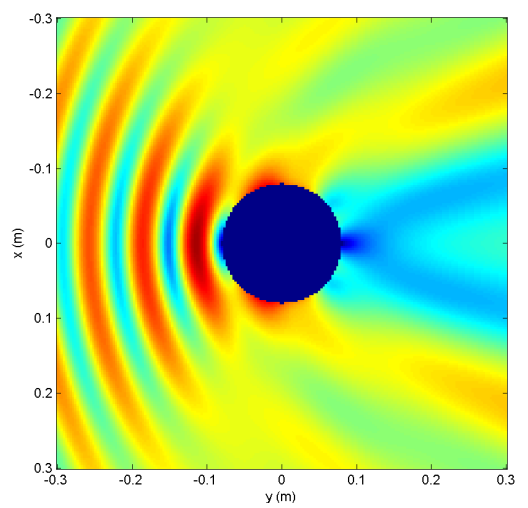

(e) $\alpha=60^{\circ}$

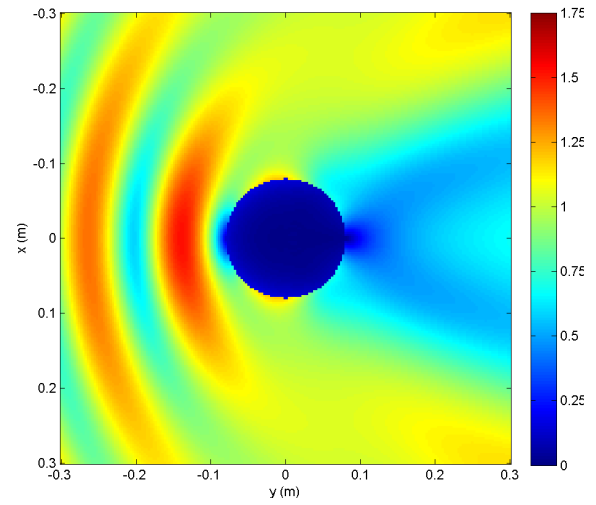

(c) $\alpha=30^{\circ}$

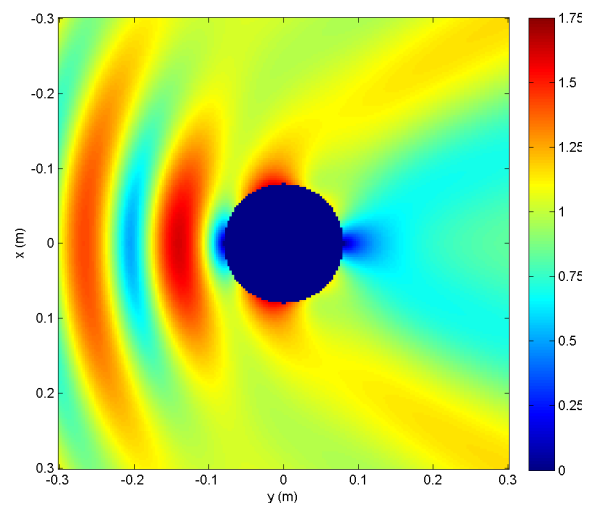

(f) $\alpha=30^{\circ}$

Fig. 3. Electric field strength $(\mathrm{V} / \mathrm{m})$ plot for TE plane wave incident on a human-body average (a, b, c) and PEC (d, e, f) cylinder at different angles.

The fields for a transverse electric (TE) plane wave is obtain by interchanging $E$ and $H$ and replacing $\mu$ by $-\frac{k^{2}}{\omega^{2} \mu}$ and multiplying the fields with $\frac{k}{\mu \omega}$. Note that there is a sign error on $c_{n}$ in [9].

For the numerical calculation the infinite series need to be truncated at a suitable number $N$, where the series have converged. Experience shows that truncating at $N=k \rho+20$ yields very accurate results. To check the validity of the numerical code the fields at the boundary between the cylinder and free space was calculated and the tangential component was found to be continuous. The incident field strength was chosen to be $1 \mathrm{~V} / \mathrm{m}$.

\section{NUMERICAL RESULTS}

The results are seen for the TM polarization and the TE polarization in Fig. 2 and Fig. 3, respectively.

For the TM polarization, for normal incidence, $\alpha=90^{\circ}$, it is seen that the fields are almost the same for the PEC and the human-body cylinder. The only slight difference is the front reflection. Gradually, as the angle of incidence $\alpha$ decreases the difference becomes larger as most clearly seen for the plots of the electric field at an incidence angle of $\alpha=30^{\circ}$. It is seen that the fields on the back side are higher for the human-body cylinder than for the PEC cylinder. The field strength on the back side increases for lower angles of incidence. In front of the cylinder the reflection is seen to be much more powerful for the PEC cylinder than for the human-body cylinder.

For the TE polarization the fields are more different at normal incidence, i.e., $\alpha=90^{\circ}$. The reflection is seen to be stronger in front of the PEC cylinder than for the human-body cylinder. On the back side the fields are significantly higher for the PEC cylinder. As the angle of incidence decreases the differences between the PEC and human-body cylinder increases. The fields on the back side are significantly higher for the PEC cylinder.

In general, the TM polarization seem to give quite similar results for the PEC and human-body cylinder whereas the difference is slightly larger for the TE polarization. It is noted that the situation in [6] is actually TM polarized and therefore there is a good correspondence with the results found in this reference. Furthermore, the differences in both cases become more pronounce when the angle of incidence decreases.

\section{CONCLUSION}

The accuracy of the use of PEC as an approximation of the human body has been investigated. It was found that for normal incidence and TM polarization the human body is very well modeled by PEC. At normal incidence and TE polarization the human body is quite well modeled by PEC. As the angle of incidence become more oblique, the 
differences between PEC and actual human-body parameters become more profound. For very oblique angles of incidence and TE polarization the validity of approximating the humanbody by PEC is questionable.

\section{REFERENCES}

[1] Y. Hao, A. Alomainy, Y. Zhao, C. G. Parini, Y. I. Nechayev, P. S. Hall, and C. C. Constantinou, "Statistical and Deterministic Modelling of Radio Propagation Channels in WBAN at 2.45GHz," in Antennas and Propagation Society International Symposium 2006, IEEE, 2006, pp. 2169-2172.

[2] Y. Zhao, Y. Hao, A. Alomainy, and C. G. Parini, "UWB On-Body Radio Channel Modeling Using Ray Theory and Subband FDTD Method," IEEE Trans. Microwave Theory Tech., vol. 54, no. 4, pp. 1827-1835, apr 2006.

[3] R. Chandra and A. J. Johansson, "An Analytical Link-Loss Model for On-Body Propagation Around the Body Based on Elliptical Approximation of the Torso With Arms' Influence Included," IEEE Antennas Wirel. Propag. Lett., vol. 12, pp. 528-531, apr 2013.

[4] — "A Link Loss Model for the On-body Propagation Channel for Binaural Hearing Aids," IEEE Trans. Antennas Propagat., vol. 61, no. 12, pp. 6180-6190, dec 2013.
[5] S. H. Kvist, J. Thaysen, and K. B. Jakobsen, "Ear-to-Ear On-Body Channel Model for Hearing Aid Applications," IEEE Transactions on Antennas and Propagation, vol. 63, no. 1, pp. 344-352, jan 2015.

[6] M. Ghaddar, L. Talbi, and T. A. Denidni, "Human Body Modelling for Prediction of Effect of People on Indoor Propagation Channel," Electronics Letters, vol. 40, no. 25, pp. 1592-1594, dec 2004.

[7] S. Gabriel, R. W. Lau, and C. Gabriel, "The Dielectric Properties of Biological Tissues: III. Parametric Models for the Dielectric Spectrum of Tissues," Physics in Medicine and Biology, nov 1996.

[8] I. S. C. C. . IEEE, "IEEE Recommended Practice for Determining the Peak Spatial-Average Specific Absorption Rate (SAR) in the Human Head From Wireless Communications Devices: Measurement Techniques," dec 2003

[9] B. R. Levy and J. B. Keller, "Diffraction by a Smooth Object," Communications on Pure and Applied Mathematics, vol. 12, no. 1, pp. 159-209, 1959.

[10] J. R. Wait, "Scattering of a Plane Wave From a Circular Dielectric Cylinder at Oblique Incidence," Canadian Journal of Physics, vol. 33, no. 5, pp. 189-195, 1955. 